\title{
Publishing particulars of the paper under discussion
}

Vol 58 (1) 2016, Pages 26-33, Paper 1187:

The identification and treatment of poor durability Karoo dolerite base course aggregate - evidence from case studies

http://dx.doi.org/10.17159/2309-8775/2016/v58n1a3

R C Leyland, M Momayez, J L van Rooy

\section{COMMENT}

Table 1 (referencing COLTO 1998) of the above-mentioned technical paper incorrectly states that the PI shall be $<12$ when the PI is determined on the $-0.075 \mathrm{~mm}$ fraction because $-0.425 \mathrm{~mm}$ fraction is non-plastic. COLTO requires that the PI of

\section{DISCUSSION}

\section{JOURNAL OF THE SOUTH AFRICAN INSTITUTION OF CIVIL ENGINEERING}

Vol 58 No 3, September 2016, Pages 45-46, Paper 1187

Table 1 Discussion Pre-1994 results pertaining to base course sources

\begin{tabular}{|c|c|c|c|c|}
\hline Type of stone & Area & Sample number & PI $-0.425 \mathrm{~mm}$ & PI $-0.075 \mathrm{~mm}$ \\
\hline \multirow{3}{*}{ Dolerite } & SE Transvaal & 1 & 1.7 & 7.9 \\
\hline & SE Transvaal & 2 & 0.6 & 3.9 \\
\hline & OFS & 3 & 3.1 & 9.1 \\
\hline \multirow{2}{*}{ Andesite } & S Transvaal & 4 & 5.7 & 9.2 \\
\hline & PWV & 5 & SP & 6.0 \\
\hline \multirow{2}{*}{ Norite } & N Transvaal & 6 & 1.9 & 15.4 \\
\hline & N Transvaal & 7 & 1.0 & 4.8 \\
\hline \multirow{3}{*}{ Granite } & PWV & 8 & 1.3 & 6.6 \\
\hline & E Transvaal & 9 & NP & 2.9 \\
\hline & NE Transvaal & 10 & 1.4 & 5.5 \\
\hline \multirow{8}{*}{ Quartzite } & E Transvaal & 11 & 2.5 & 7.7 \\
\hline & OFS -11 tests & 12 & $0-4$ & $7-13$ \\
\hline & PWV & 13 & 4.0 & 6.0 \\
\hline & PWV & 14 & SP & 4.0 \\
\hline & N Transvaal & 15 & NP & 12.0 \\
\hline & W Transvaal & 16 & SP & 5.0 \\
\hline & Natal & 17 & SP & 7.0 \\
\hline & Natal & 18 & SP & 6.0 \\
\hline Dwyka tillite & S Natal & 19 & 5.0 & 10.0 \\
\hline \multirow{7}{*}{ Malmesbury hornfels } & W Cape & 20 & 2.1 & 13.7 \\
\hline & W Cape & 21 & SP & 10.4 \\
\hline & W Cape & 22 & 3.1 & 11.0 \\
\hline & W Cape & 23 & SP & 12.5 \\
\hline & W Cape & 24 & NP & 3.0 \\
\hline & W Cape (G2) & 25 & 3.0 & 8.0 \\
\hline & W Cape (on R.O.C.) & 26 & 4.0 & 6.0 \\
\hline Felsite & E Transvaal & 27 & SP & 7.0 \\
\hline
\end{tabular}




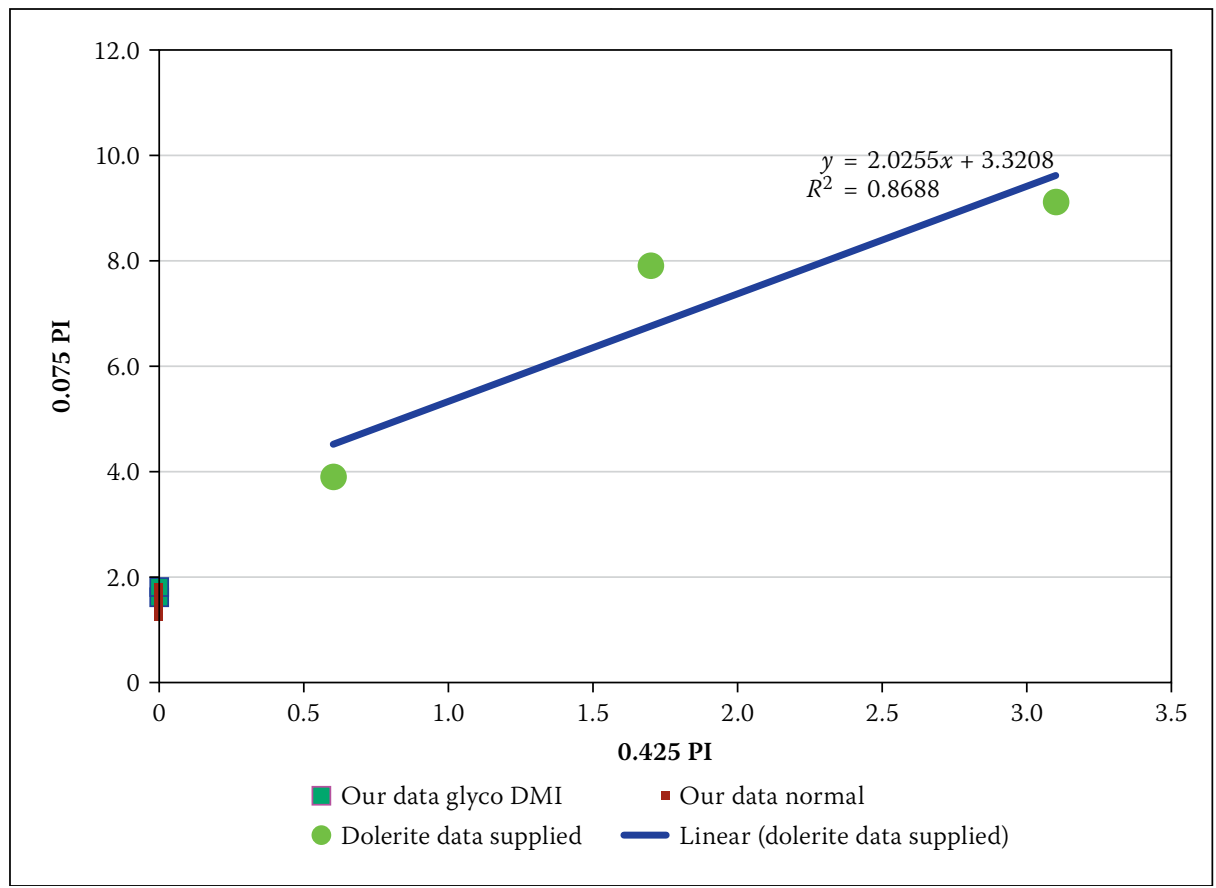

Figure 1 Discussion Plotted data from dolerite samples in Table 1 above, suggesting that an NP $(" 0$ ") result for $\mathrm{PI}$ on $-0.425 \mathrm{~mm}$ fractions would equate to a $\mathrm{Pl}$ of 3.3 on the $-0.075 \mathrm{~mm}$ fractions, which is above the value observed by us (the authors) in our original paper; the limited data supplied does, however, not make the trend very reliable

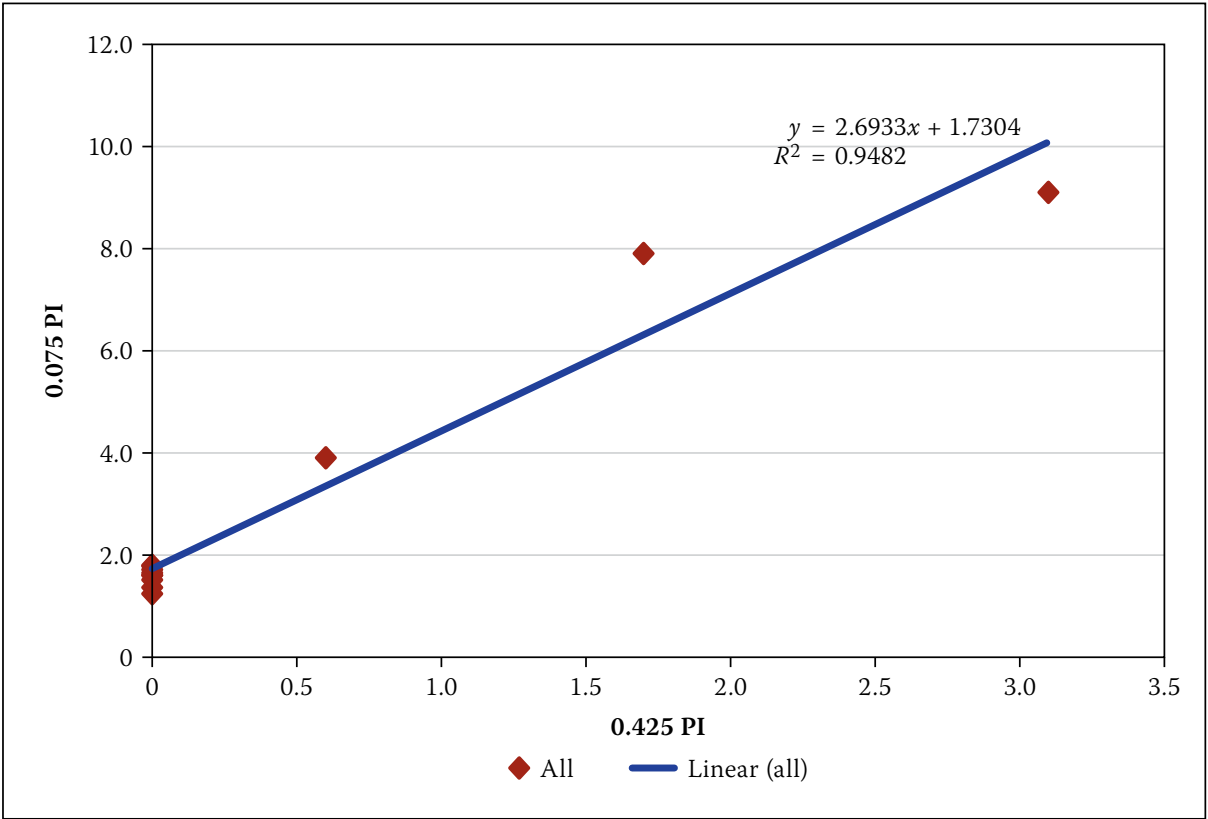

Figure 2 Discussion Following on Figure 1, if we (the authors) include our original data in the trend analysis, then an even better linear correlation is obtained

on experience, as well as the results in Table 1 (above) pertaining to base course sources at the time (pre-1994), made available by the Aggregate and Sand Producers' Association of South Africa who were kept in the picture regarding various changes to especially base-course specifications to accommodate increasing pavement structural demands, which were not adequately
It would be most interesting to hear from the authors whether these tests were carried out for the projects in question, and for them to provide such details.

Etienne M de Villiers Pr Eng divvies@iafrica.com

\section{RESPONSE FROM AUTHORS}

Thank you for pointing out the error in Table 1 of our paper. The intention was not to provide an incorrect specification, but rather to illustrate that if the $-0.425 \mathrm{~mm}$ fraction was non-plastic, the $-0.075 \mathrm{~mm}$ material was also tested to ensure that that material PI was not above the specified value of 12 . We agree that it would have been beneficial to test the $-0.075 \mathrm{~mm}$ fraction of each sample, but unfortunately this was not possible for reasons including budgets and sample volumes.

In all the cases where we obtained NP results for $-0.425 \mathrm{~mm}$ fractions (seven results in total) the PI of the $-0.075 \mathrm{~mm}$ fraction ranged from 1.2-1.8. Similarly we did testing of PI on glycol-treated DMI samples, and obtained a PI $(-0.075 \mathrm{~mm})$ range of 1.6-1.8 (four results) when the PI of the $-0.425 \mathrm{~mm}$ fraction was NP. Our dolerite results therefore show a strong correlation between PI of $-0.425 \mathrm{~mm}$ and $-0.075 \mathrm{~mm}$ fractions when the PI of the former is NP.

Plotting the data you provided for the dolerite samples only (Table 1 Discussion), a trend can be seen which suggests that an NP ("0") result for PI on $-0.425 \mathrm{~mm}$ fractions would equate to a PI of 3.3 on the $-0.075 \mathrm{~mm}$ fractions. This value is above that observed by us. The limited data supplied does, however, not make this trend very reliable.

Additionally, if we include our data in the trend analysis, an even better linear correlation is obtained (see Figures 1 and 2 alongside).

In conclusion, it would have been ideal if we could have added to the data, thereby better defining the trend, but unfortunately that is not the case. This provides a useful consideration for future testing and research projects. fraction, as obtained for different sources of the same rock type, the outcome definitely not being directly related to the plasticity index of the $-0.425 \mathrm{~mm}$ fraction. 